\title{
Combinatorial Approaches With Checkpoint Inhibitors to Enhance Anti-tumor Immunity
}

\author{
Barbara Seliger* \\ Institute of Medical Immunology, Martin Luther University Halle-Wittenberg, Halle (Saale), Germany
}

Treatment of cancer patients has been recently revolutionized by the application of various immunotherapeutics. However, the response rates are still limited ranging between approximately 20 and $40 \%$ suggesting that combinations of immunotherapy with conventional treatment, like chemotherapy, radiation, epigenetic modulators, targeted therapies using small molecules as well as other (immuno) therapeutics, might be an option to increase systemic anti-tumor immunity. It is postulated that different non-immune based therapies in combination with immunotherapies could reprogram the immune suppressive tumor microenvironment and enhance the immunogenicity

OPEN ACCESS

Edited by:

Lionel Apetoh

Institut National de la Santé et de la

Recherche Médicale

(INSERM), France

Reviewed by:

Benjamin Frey,

University of Erlangen Nuremberg,

Germany

Behjatolah Monzavi-Karbassi, University of Arkansas for Medical

Sciences, United States

*Correspondence: Barbara Seliger

barbara.seliger@uk-halle.de

Specialty section:

This article was submitted to Cancer Immunity and Immunotherapy, a section of the journal

Frontiers in Immunology

Received: 05 November 2018 Accepted: 18 April 2019 Published: 22 May 2019

Citation:

Seliger B (2019) Combinatorial

Approaches With Checkpoint Inhibitors to Enhance Anti-tumor Immunity. Front. Immunol. 10:999. doi: 10.3389/fimmu.2019.00999 of tumor cells leading to an improved therapeutic efficacy and a better patients' outcome. Despite there exist various examples of increased objective responses achieved by adding these different therapies to immunotherapies, strategies for rational and evidence-based design of checkpoint inhibitor combinations to maximize the clinical benefit for patients are urgently required. Therefore, the main purpose of this review is to summarize recent results obtained from experimental models and clinical trials to enhance tumor immunogenicity by combining immunotherapy with other therapeutic options to maximize patients' outcome and minimize adverse events.

Keywords: immune checkpoints, immunotherapy, tumor, inhibitors, biomarkers

\section{INTRODUCTION}

During the last decade novel tumor immunotherapeutic approaches have recently revolutionized the cancer treatment. In particular the clinical success of monoclonal antibodies (mAb) directed against immune checkpoint (iCP) molecules, such as the T lymphocyte antigen 4 (CTLA-4) and the programmed cell death protein 1/programmed cell death ligand 1 (PD-1/PD-L1) pathway, was a breakthrough achievement resulting in the Nobel Price of Medicine 2018. The anti-CTLA-4 mAb Ipilimumab was the Food and Drug Administration (FDA) approved checkpoint inhibitor (iCPI) followed by approval of Pembrolizumab, Nivolumab, and Cemiplimab directed against PD-1, in 2014, 2016, or 2018, respectively, for non-small cell lung cancer (NSCLC), melanoma, renal cell carcinoma (RCC), bladder cancer and/or squamous cell skin cancer and the anti-PD-L1 mAbs Durvalumab, Atezolizumab, and Avelumab in 2017 after promising results in NSCLC, urothelial carcinoma and Merkel cell carcinoma (1-3). Currently, a number of other "next generation" iCPIs directed against e.g., the lymphocyte-activation gene 3 (LAG-3), the T cell immunoglobulin and mucin domain-3 (TIM-3) and B7-H4, are tested in experimental models and/or clinical trials $(4,5)$. Despite the rapid progress in approvals for iCPIs in an expanding spectrum of malignancies, there exists accumulating evidence that approximately only one-third of patients achieve a durable 
long-term response as stand-alone intervention with iCPIs $(6,7)$. This might be due to primary and acquired resistance and thus limit the efficacy of the treatment (8-10) suggesting that a high frequency of patients do not respond to iCPI alone. In contrast, recent efforts combining iCPIs with conventional and other (immuno)therapies achieved response rates of over $50 \%(11,12)$, since they not only mediate anti-neoplastic effects by cytotoxic and cytostatic mechanisms, but also by local as well as systematic modulation of immunological functions $(13,14)$.

Currently, a number of preclinical and clinical trials for iCPIs across all tumor types coupled with a second immunotherapeutic modality or combined with e.g., chemotherapy, targeted therapies, radiation therapy (RT), epigenetic modulators, inhibitors of histone deacetylases (HDAC), DNA methyltransferases (DNMT), or cyclin-dependent kinases 4 and 6 (CDK4/6), are conducted $(13,15)$.

So far, 7 iCPIs and 1 combination immunotherapy regimen have been approved by the FDA since $2011(16,17)$. However, it is very obvious that these approaches will increase by rationally designed synergistic combinations based on an individualized patients' setting (14). Therefore, biomarkers are urgently required (i) to select patients who will benefit and respond to treatment and (ii) to identify the best combinations of agents for each patient to improve response rates, enhance treatment efficacies and mitigate toxicities $(18,19)$. The aim of these combinations are to enhance effector function of immune cells leading to tumor elimination, to modulate the immune suppressive tumor microenvironment (TME), to recruit $\mathrm{T}$ cells to the tumor, and to revert immune escape mechanisms (20). It is suggested that overcoming the different resistance mechanisms might be one major key for enhancing the efficacy of immunotherapies. This

\footnotetext{
Abbreviations: ADCC, antibody dependent cell mediated cytotoxicity; AML, acute myeloid leukemia; APC, antigen presenting cell; CAF, cancer-associated fibroblast; CDK4/6, cyclin-dependent kinase 4 and 6; CLL, chronic lymphatic leukemia; CP, cyclophosphamide; CRC, colorectal cancer; CTL, cytotoxic T lymphocyte; CTLA-4, T lymphocyte antigen 4; DC, dendritic cells; DNMT, DNA methyltransferase; ECM, extra cellular matrix; EGF, epidermal growth factor; EGF-R, EGF receptor; Fas, factor associated with suicide; FDA, Food and Drug Administration; HDAC, histone deacetylase; HDACi, HDAC inhibitor; HIF, hypoxia inducible factor; HNSCC, head and neck squamous cell cancer; ICAM-1, intracellular adhesion molecule-1; ICM, tumor extracellular matrix; iCP, immune checkpoint; iCPI, immune checkpoint inhibitor; IDO, indoleamine 2,3 dioxygenase; IFN, interferon; Ig, immunoglobulin; IL, interleukin; KIRs, killer inhibitory receptor; LAG-3, lymphocyte-activation gene 3; mAb, monoclonal antibody; MDSC, myeloid-derived-suppressor cell; MHC, major histocompatibility complex; MMP, metalloproteinase; MSC, mesenchymal stem cell; NK, natural killer; NSCLC, non-small cell lung cancer; OS, overall survival; PBMNC, peripheral blood mononuclear cell; PD-1, programmed cell death protein 1; PD-L1, programmed cell death ligand 1; PFS, progression-free survival; RCC, renal cell carcinoma; RFS, relapse-free survival; RT, radiation therapy; sting, stimulator of interferon genes; TA, tumor antigen; TAA, tumor associated antigens; TAF, tumor associated fibroblasts; TAM, tumor-associated macrophages; TAN, tumor-associated neutrophil; TCR, T cell receptor; TEX, tumor-derived exosomes; TGF, transforming growth factor; TIL, tumor infiltrate lymphocyte; TIM-3, T cell immunoglobulin and mucin domain-3; TKI, tyrosine kinase receptor; TLR, toll-like receptor; TME, tumor microenvironment; TNBC, triple negative breast cancer; Treg, regulatory T cells; TREX1, three prime repair exonuclease 1; VEGF, vascular endothelial growth factor; VEGF-R, vascular endothelial growth factor receptor; VISTA, V-domain Ig suppressor of T cells activation.
}

report summarizes the rational for the design of some promising regimens combining iCPIs with other treatment options and future strategies in order to attack the primary tumor, but also cancer cells within the patients' body including cancer stem cells, metastasis and circulating tumor cells (Figure 1).

\section{COMBINATION OF IMMUNOTHERAPIES WITH OTHER IMMUNOTHERAPIES}

Due to the increase in available iCPIs and other immunotherapeutics, such as novel iCPIs, e.g., antagonistic antibodies directed against LAG-3, V-domain Ig suppressor of $\mathrm{T}$ cells activation (VISTA), and $\mathrm{T}$ cell immunoglobulin and mucin domain-3 (TIM-3) or activating antibodies against e.g., OX40, 4-1BB, ICOS, and CD40, novel vaccines, cytokines, anti-killer inhibitory receptors (KIR), oncolytic viruses, and cellular therapies, an abundance of possibilities exists, which are currently studied in animal models and/or clinical trials $(21,22)$. The rational for these combinations are the distinct molecules, but complementary pathways, which are targeted and therefore might result in synergistic effects. The following part briefly summarizes some selected major concepts.

\section{Combinations of iCPIs With Other iCPIs}

Inhibition of CTLA-4 and PD-1 act on distinct pathways, e.g., central vs. peripheral immunity, the blockade of both pathways is complementary suggesting that simultaneous inhibition of these targets have additional anti-tumor activity (23). The first iCPI combination employed was Ipilimumab with anti-PD-1 in melanoma resulting in an increased efficacy, but also high levels of adverse events $(23,24)$. Examples of other iCPI combination strategies include anti-PD-1 and anti-PD-L1 antibodies in combination with established or novel iCPIs, such as anti-TIM-3, anti-OX40, anti-LAG-3, and anti-VISTA, respectively.

\section{Combination of Immunotherapies With Vaccines}

Despite cellular therapies are still in their infancy compared to iCPIs the combination of different cellular therapies with antibodies directed against iCPs is promising and first results from in vivo models and clinical trials exist. Currently, a number of clinical trials using two or more combinations are investigated including different whole cell-based vaccines like tumor-infiltrating lymphocytes (TIL), T cell receptor (TCR), or chimeric antigen receptor (CAR)-modified $\mathrm{T}$ cells and dendritic cell (DC)-based vaccines (25). Interestingly, another novel approach is the co-delivery of PD-L1 siRNA with a DCbased mRNA vaccine, which caused a downregulation of PDL1 in tumor-antigen presenting DCs thereby boosting antitumor responses (26). Despite preliminary investigations gave promising results, the major challenges of the combination of whole cell-based vaccines with iCPIs are adverse events due to toxicities and autoimmunity, which have to be reduced (27). It is also noteworthy that a synergistic effect of a synthetic DNA vaccine with antibodies directed against iCPIs was 


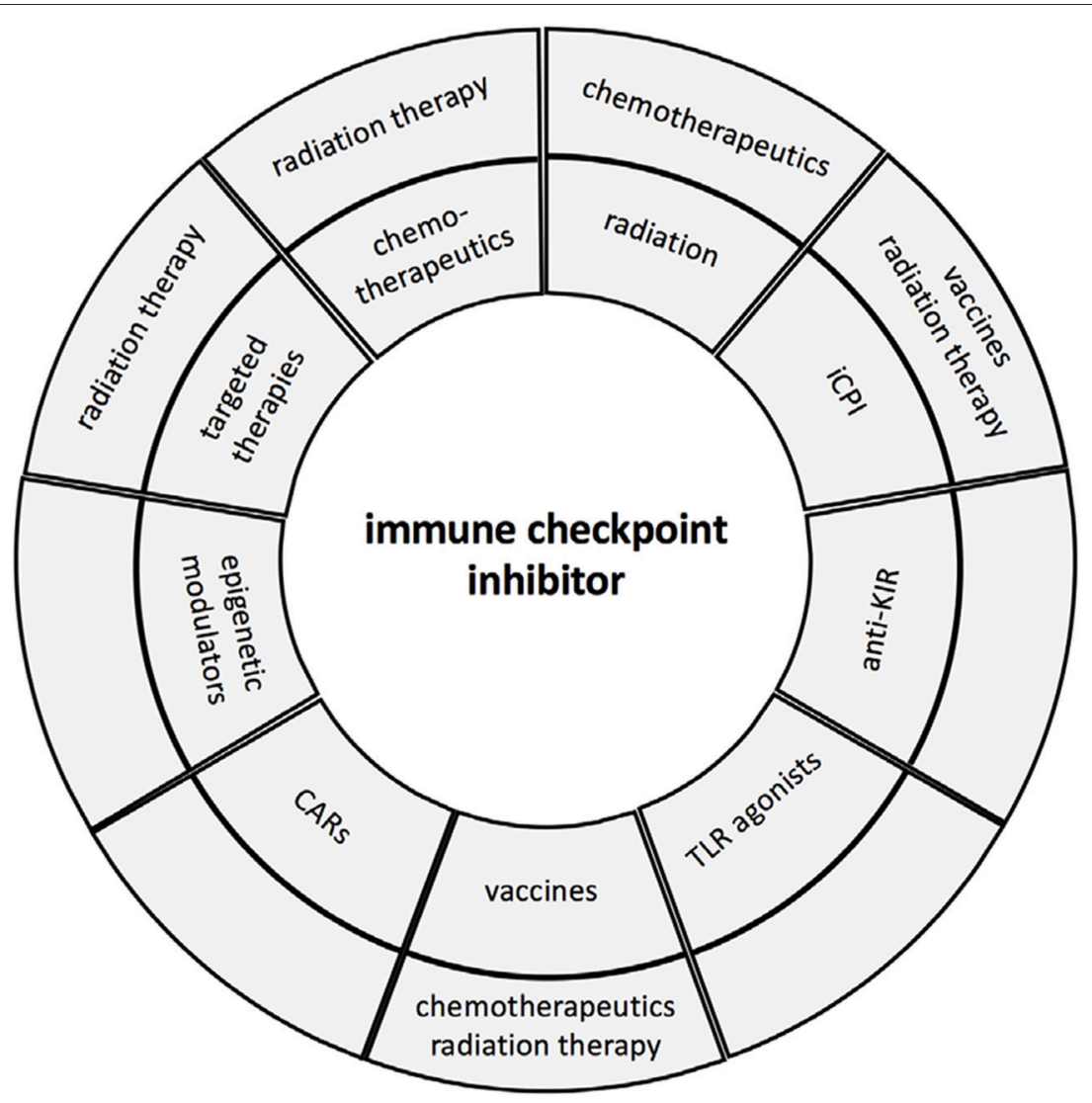

FIGURE 1 | Immune check point inhibitor therapy and combinations. The major combinations of iCPIs and other therapies are summarized and presented in the first circle, while the second circle illustrates the triple combinations currently in clinical trials.

found, which was due to alterations of the immune regulatory environment (28).

\section{Combinations of iCPIs With IgG Antibodies}

In addition to cellular therapies, the use of antibody dependent cell mediated cytotoxicity (ADCC) has recently been suggested as a promising combination with iCPIs (29). Immunoglobulin (Ig) G1 monoclonal antibodies (mAbs) have the highest capacity to induce ADCC in comparison to Ig isotypes (30-32). Thus, a number of IgG1 mAbs, such as Trastuzumab, Cetuximab and Rituximab, directed against the HER-2/neu, EGF-R, or the B cell-restricted antigen CD20, have been developed and were used for the treatment of different tumor types, such as colorectal cancer (CRC), head and neck squamous cell carcinoma (HNSCC), Non-Hogkin lymphoma and chronic lymphatic leukemia (CLL), respectively. These mAbs exert antitumor properties by inhibition of tumor growth, but modulation the immune cell activity (33-35). A combination of iCPIs with IgG1 mAbs can boost the innate and adaptive anti-tumor activity, recruit effectors, alters the composition of the TME by elimination of dysfunctional lymphocytes thereby enhancing the efficacy, durable responsiveness and patients' survival as shown for CRC and HNSCC (29). However, the inhibitor mediated ADCC and the recruitment of $\mathrm{CD}^{+}$cytotoxic $\mathrm{T}$ lymphocytes
(CTL) to the tumor is associated with negative feedback loops, such as enhanced infiltration with Tregs and MDSC as well as an increased expression of different iCPIs (29). Thus, co-targeting of both immune suppressive mechanisms and the synergistic activity of e.g., Cetuximab and iCPIs might improve the outcome of patients. Indeed, a number of ongoing studies investigate the combination Cetuximab with various iCPIs including Avelumab in order to generate a beneficial immune effect.

\section{COMBINATION OF ICPI WITH CONVENTIONAL TREATMENT AND INCREASED SUSCEPTIBILITY OF TUMOR CELLS TO LETHAL SIGNALS FROM CTL MEDIATED BY DEATH RECEPTORS}

\section{RT With Immunotherapy-and First Results}

RT is used a standard treatment of many cancers by reducing the risk of recurrences after surgery as curative treatment of localized tumors or as palliative treatment to reduce the bulk of tumors. In addition, so called abscopal effects were demonstrated outside of the irradiated field (36). While RT can be immune suppressive, it can also enhance antigenicity and adjuvanticity by promotion of the release of tumor antigens (TA) combinations of 
immunotherapy with RT has been suggested (37-39). Although durable responses are rare, most patients benefit from this treatment by distinct mechanisms (40) including RT-mediated enhancement of $\mathrm{T}$ cell responses and changes in the TME composition. For example RT can reprogram the anti-myeloid TME to a pro-myeloid TME allowing recruitment of antigen presenting cells (APC) and T cells mediated by the induction of type I IFN due to activation of stimulator of interferon genes (STING) and its upstream signaling pathways. Cross presentation of tumor associated antigens (TAA) to CTL results in activation of $\mathrm{T}$ cells, which release IFN- $\gamma$ known to increase and/or induce major histocompatibility complex (MHC) class I surface expression, (41-43) the factor associated with suicide (Fas) and the intracellular adhesion molecule-1 (ICAM-1) (4446) involved in elimination of tumor cells. However, TFG- $\beta$ is also released during RT, which inhibits immune responses by decreasing the capacity of DC to present TAA, T cell function, and HLA class I antigen expression on tumor cells thereby promoting tumorigenesis, which is associated with poor clinical outcome of patients (47). Other radiation induced cytokines, chemokines, and growth factors influence the balance between immune clearance and immune tolerance in the TME, play a dual role on the tumor infiltrating immune cell repertoire and on the modulation of anti-tumoral immune responses (48). In addition, RT can upregulate PD-1 and PD-L1 on tumor and immune cells $(49,50)$ providing a window of opportunity for anti-PD-L1/PD-1 inhibitor treatment by diminishing resistance to RT and upregulating the sensitivity to iCPI (51). Thus, iCPIs might work synergistically with the RT-induced T cell response through redundant pathways.

Indeed, preclinical data suggest that different immune modulators synergize with RT leading to tumor regression (52). For example, the combination of RT with an anti-CTLA-4 $\mathrm{mAb}$ not only increased the density of TILs and the $\mathrm{CD} 8^{+}$ vs. $\mathrm{CD}^{+} \mathrm{T}$ cell ratio in a murine carcinoma model, but also resulted in a more oligoclonal $\mathrm{T}$ cell repertoire required to achieve tumor rejection thereby supporting the synergic activity of RT and CTLA-4 blockade (53). The feasibility combining focal radiation with systemic TGF- $\beta$ blockade due to increased peripheral blood mononuclear cell (PBMNC) and central memory $\mathrm{CD}^{+} \mathrm{T}$ cell counts as well as abscopal effects was demonstrated in a metastatic breast cancer model (54). A combination of RT with STING agonists enhanced T cell priming and reduced tumor growth $(41,55)$. In sum, RT has the potential to efficiently induce the secretion of type I IFN and enhances the expression of the three prime repair exonuclease 1 (TREX1) known to degrade cytosolic double stranded DNA, which represents a key regulator of the cellular response to RT. TREX1 controls the immunogenicity of radiated cells by amplifying the immunogenicity of tumor cells and the abscopal responses (55).

Since tumors are often infiltrated by suppressive cells expressing high levels of $\mathrm{PD}-\mathrm{L} 1$, high radiation doses might be more effective in eliminating tumor cells. So far, the dose and fractionation of RT in immune modulation has not been analyzed in detail. However, there exists evidence that the recruitment of DC to tumor cells is dependent on the RT dose and fractionation.
Thus, RT must be administered at optimal doses, schedules and sequences to obtain a robust anti-tumor immunity.

In this context, a number of clinical trials have been completed, are currently recruiting or planned in different cancer types combining different FDA-approved iCPIs with radiotherapy including several radiation doses (56-58) (see ClinicalTrials.gov). Chemo-radiation combined with anti-PD-L1 antibody or placebo demonstrated a progression-free survival of PD-L1 antibody treated patients compared to placebo (59) demonstrating a beneficial effect of RT with iCPIs. This is further in line with improved anti-CTLA- 4 mediated $\mathrm{T}$ cell responses upon in situ vaccination by RT (60). Furthermore, a combination of in situ vaccination with intra-tumoral injection of tumor-specific antibodies and systemic CTLA4 improved primary tumor response and survival in an experimental model (61).

\section{Combination of Chemotherapy With Immunotherapeutic Approaches}

Chemotherapeutic agents (taxanes, cyclophosphamides) can promote anti-tumor immune responses by enhancing proinflammatory cytokines and exerting immune modulatory effects on tumor cells, such as e.g., an upregulation of HLA class I antigens, as well as on the TME, like depletion of myeloidderived suppressor cells (MDSCs) and regulatory T cells (Tregs) (62). A major objective is to convert so called "cold" nonimmunogenic tumors into "hot" immunogenic tumors, which are more sensitive to immunotherapy. Thus, chemotherapybased immune modulation prior to iCPI treatment appears promising. In two experimental murine models of CRC (CT26) and RCC (RENCA) combining cyclophosphamide (CP) with CTLA-4 blockade had contrasting effects. In CT26-bearing hosts, CP augments the anti-tumor effect of ant-CTLA-4, while in RENCA this combination had only a marginal effect (63). In a clinical phase Ib study of advanced or metastatic NSCLC patients, Atezolizumab followed by chemotherapy significantly increased the response rate of NSCLC patients (NCT00527735) (64). Furthermore, 50 metastatic triple negative breast cancer (TNBC) patients treated with low-dose chemotherapy followed by Nivolumab demonstrated an increased overall survival (OS) with low toxicity, which was better than anti-PD-1 monotherapy (NCT02499367, J Clin. Oncol. 36, no. 15_suppl. (May 2018) 1012-1012; doi/10.1200/JCO.2018.36.15_suppl.1012). In sum, low-dosage immunogenic chemotherapies plus checkpoint blockers enhance tumor immunogenicity, which might revert tumor relapse by eliminating dormant cancer cells and thus should be used for combination therapies. This option was in line with results of a phase III clinical trial in NSCLC patients treated with Pembrolizumab in combination with chemotherapy, demonstrating a significantly increased OS and PFS compared to chemotherapy alone with an overall response rate of 48 vs. $19 \%$ with no change in adverse events (NCT02578680). Thus, this combination was synergistic and exhibits an acceptable safety profile $(65,66)$. It is noteworthy that OS of patients was improved independent of PD-L1 expression levels of tumor cells, which argue for combine iCPIs with chemotherapy replacing 
chemotherapy as the standard of care for first-line treatment of metastatic NSCLC.

\section{COMBINATION OF IMMUNOTHERAPY WITH TARGETED THERAPIES}

Different growth factors and angiogenic factors and their receptors, including EGF/EGF-R, VEGF/VEGF-R, and angiopoietin, have been shown to affect the innate and adaptive immune response and induce immune suppression $(12,67)$. Based on the functions described, inhibition of these pathways might offer novel combination opportunities and synergies with iCPI (68). While the efficacy of immunotherapy is often associated with a reduced recruitment of blood vessels and activated cytotoxic $\mathrm{T}$ cells, anti-angiogenic therapy could reprogram the immune suppressive TME by normalizing the vasculature and increased $\mathrm{T}$ cell recruitment thereby enhancing the efficacy of cancer treatment. However, potent inhibition of angiogenesis increases hypoxia, which negatively interferes with immune responses (69). Thus, the anti-cancer immune response is impaired and vascular normalization by anti-angiogenic inhibitors could therefore revert the immune suppression and increase the efficacy of chemotherapy and immunotherapy (70-73). Indeed, a number of ongoing clinical trials combine anti-angiogenic therapy with iCPI alone or even in combination with chemotherapy (74). These combinations have synergistic effects and improve response rates, but some combinations exhibit a high toxicity (75).

Some targeted agents such as B-RAF and MEK inhibitors are associated with immune modulatory activity and might act synergistic with iCPIs. The BRAF inhibitor Vemurafenib was combined with anti-CTLA- $4 \mathrm{mAb}$, but this combination had adverse effects, while combining Vemurafenib with a PD-L1 inhibitor and kinase/ERK inhibitor improved the treatment efficacy (76-78). Other therapeutic intervention with iCPIs include inhibitors directed against indoleamine (IDO) phosphoinositid-3-kinase- $\gamma$ (PI3K- $\gamma$ ) (79), and colony stimulating factor 1 , which lead in combination with anti-PD1 to a regression of all tumors and $90 \%$ survival after 90 days (80). Inhibitors directed against the molecules CDK4/6, which are essential for the initiation and development of breast cancer and ALL, demonstrated growth inhibition in various cancers as well as induction of anti-tumor immunity by enhancing TAA expression and inhibiting regulatory $\mathrm{T}$ cell proliferation (81, 82). Combining CDK4/6 inhibitors with iCPI treatment led to complete tumor regression and immunological memory in an experimental murine breast cancer model suggesting this treatment regimen as a promising option (83).

\section{EPIGENETIC MODULATORS}

Epigenetic modulators, like inhibitors of histone deacetylases $\left(\mathrm{HDAC}^{+}\right.$) or DNA methyltransferases (DNMT) are currently used for the therapy of different tumor entities. This is based on the fact that (i) HDAC is overexpressed in tumors, (ii) inhibition of HDAC negatively interferes with the expansion of MDSCs, (iii) tumor antigens (TA) are often methylated and thus not presented via HLA class I and class II molecules, and (iv) hypomethylating agents as well as HDACi have diverse immune modulating effects by e.g., upregulating HLA class I and components of the IFN- $\gamma$ signal pathway (84). Since the different epigenetic modulators exhibit a low toxicity, the use of these inhibitors might increase the efficacy of single-agent immunotherapies (85). The combination of Ipilimumab with Nivolumab had synergistic effects on tumor growth with 5-azacytidine and entinostat and $>90 \%$ of CRCs and $100 \%$ of metastatic mammary tumors were illuminated. Demethylation of the PD-1 promoter on T cells by 5-azacytidine in AML patients correlated with increased PD1 expression, leading to the rational combination of DNMT inhibitor with anti-PD-1 mAbs, which are currently tested in clinical trials of NSCLC patients, but also of other cancers (86).

\section{NOVEL STRATEGIES}

Next to these options and based on the increased knowledge in the biology of cancer and immune cells and the composition of the TME, novel innovative strategies are currently discussed or studied in experimental models or clinical trials in conjunction with iCPIs. Some interesting strategies are depicted in the following part.

\section{Anti-KIR}

Next to enhancing $\mathrm{T}$ cell mediated immune responses, natural killer (NK) cells are critical effectors of the innate immune system and are able to control tumor growth (87). This has been shown e.g., in acute myeloid leukemia (AML) patients, in which the number and activity correlated with relapse-free survival (RFS) (88). NK cells express both stimulatory, but also inhibitory receptors. The Ig-like KIRs prevent NK cell activation upon binding to their ligands, principally HLA-C molecules (89). The clinical relevance of KIR inhibition was demonstrated in models of allogeneic haplo-mismatched stem cell transplantation. In the absence of KIR/KIR-ligand binding, alloreactive NK cells were able to eliminate residual leukemia (90). Recently, a number of KIR antibodies have been developed that prevent the KIR/HLA$\mathrm{C}$ interaction including e.g., IPH2101. This antibody augmented NK cell-mediated elimination of autologous human HLA-C ${ }^{+}$ AML blasts, which was confirmed in a NOD-SCID mouse model of NK cell-mediated tumor rejection. Since a correlation between PD-L1 and KIR expression was found in NSCLC and associated with a poor prognosis of these patients (91), a combination of anti-KIR and iCPIs is currently discussed.

\section{TLR Agonists}

Toll-like receptors (TLR) agonists, such as SD101 and IV270 $(92,93)$ are under investigation in solid tumors $(94,95)$ due to their ability to induce potent anti-tumor immune response. TLR agonists could activate the innate immune response and revert immune suppression and tolerance $(96,97)$. Thus, it has been suggested to combine them with iCPIs to suppress tumor growth and shape the TME. First results in a murine HNSCC model demonstrated an increased ratio of M1/ M2 macrophages, T cell clonality and recruitment of $\mathrm{CD} 8^{+} \mathrm{T}$ cells (98). 


\section{Modulators of Extracellular Matrix (ECM) in Combination With Immunotherapies}

Components of the extracellular matrix (ECM) have been shown to play a key role in the initiation and progression of tumors by regulating different steps of the cancer process (99). Matrix components representing the matrisome in the TME are produced by mesenchymal stem cells (MSC), pericytes and cancer-associated fibroblasts (CAFs) and affect anti-tumor immune response and the efficacy of immunotherapies (100). ECMs have been shown to alter the TME and modulate the differentiation, migration, infiltration as well as polarization of immune cells in the TME (101). Thus, are involved in the development of an inflamed TME by regulating the activity of Tregs and immune suppressive myeloid cells (102). A combination of matrix metalloproteinase (MMP) inhibitors with an experimental mammary cancer model delayed tumor growth, reduced metastases formation and the percentage of Tregs and MDSCs as well as microvessel density (103). Thus, ECM components might serve as biomarkers to improve patients' stratification, but also could be used as therapeutic targets in combination with immunotherapies (104).

\section{Other Novel Potential Combination Partners for iCPIs}

Based on the increased knowledge of the TME a number of potential novel co-targets for iCPI combinations have been suggested. These are the on the one hand approaches to normalize the host and immune cell metabolism by targeting e.g., cyclooxygenase (COX2). COX2 is overexpressed in different cancers $(105,106)$. The tumor-derived COX activity causes immune evasion. Interestingly, this could be reverted by a combination with iCPIs. Preclinical models demonstrated that COX inhibitors, such as aspirin, have a synergistic effect in combination with anti-PD1 in different murine experimental models leading to tumor eradication $(107,108)$.

Furthermore, exosomes known to transmit material from tumor cells to stroma and immune cells, which could lead to immune escape has been started to be therapeutically exploited either as nano-particle for drug delivery, direct exosome based immunotherapy, or removal of tumor-derived exosomes (TEX) from the periphery (109). On the other hand, it has been suggested to use TEX as tumor vaccines as a source of specific stimuli for anti-tumoral immune responses (110), but the clinical potential in monotherapy as well as in combination with other immunotherapies including iCPI has not yet been analyzed $(111,112)$.

\section{BIOMARKERS FOR PREDICTION OF RESPONSE TO ICPI AND COMBINATORIAL THERAPIES}

Due to the limited durable response to iCPI and combinations, criteria to discriminate responders from non-responders prior to the initiation of treatment as well as during treatment are urgently needed. The predictive biomarkers might allow the selection of patients who are more likely to respond, while they might also allow to detect acquired resistance mechanisms. Some reports analyzed the composition of the intra-tumoral immune cell infiltration by IHC or multispectral imaging and the immune cell repertoire of peripheral blood lymphocytes for prediction of anti-tumoral immune responses (113-119). This was extended by high throughput RNA-seq, deep sequencing of TCR, mass cytometry as well as in silico analysis using TCGA data and a systematic bioinformatics pipeline leading to a multi-dimensional analysis of the immune signature regarding the responsiveness to iCPI therapy $(120,121)$. Based on these distinct approaches, an optimized immune marker panel, and interactive bioinformatics pipeline identified a responsiveness associated predictive signature in patients treated with anti-PD1 immunotherapy (122). However, it has to be pointed out that there exists a high variability between traditional fluorescence flow cytometric analysis as well as mass cytometry. Therefore, a systematic prospective collection of peripheral blood from tumor samples is mandatory for determination of immune signatures in larger multi-center cohorts of patients treated with various iCPIs alone or in combination. This might lead to a prediction signature, which could be implemented in the clinical practice prior to immunotherapy.

\section{CONCLUSIONS}

Blockade of iCPI has been successfully applied in a number of solid tumor and hematological neoplasms resulting in an enhancement of anti-tumor immune responses by targeting immune regulatory pathways. However, only a limited number of patients benefit from these therapies, which is often associated with toxicities and side effects of an autoimmune nature. Thus, prognostic and predictive biomarkers are urgently needed to define patients, which respond to given immunotherapy regimens with minimal toxicity. So far, tumor mutational burden (TMB), the immune cell infiltration as well as the expression of iCPs, such as PD-L1, have been discussed to be predictive for checkpoint blockade response. In addition, the list of combinations of iCPI with other therapies is extensive and despite the enthusiasm and potential of iCPI combination therapies, it further underlines the need to identify biomarkers in order to select patients undergoing immunotherapy combinations to provide a survival benefit for more patients and reduced adverse effects. Recent data suggest that next to the integration of TMB, iCPI expression and immune cell infiltration, host genetics, microsatellite instability, neo-antigen loss, the non-cellular composition of the TME, and the microbiome, should be analyzed. Thus, not only a standardized and optimized (immune)monitoring is crucial for tailoring immunotherapies, but it should also address the dynamics of immune response, posttranslational modifications, the contexture of immune and tumor cells as well as physical factors of the TME, e.g., hypoxia and $\mathrm{pH}$. Overcoming these challenges and the implementation of new agents and combinatorial strategies are currently the major research focus in iCPI treatment to enhance their efficacy and avoid resistances. 


\section{AUTHOR CONTRIBUTIONS}

The author confirms being the sole contributor of this work and has approved it for publication.

\section{REFERENCES}

1. Mellman I, Coukos G, Dranoff G. Cancer immunotherapy comes of age. Nature. (2011) 480:480-9. doi: 10.1038/nature10673

2. Migden MR, Rischin D, Schmults CD, Guminski A, Hauschild A, Lewis KD, et al. PD-1 blockade with cemiplimab in advanced cutaneous squamous-cell carcinoma. N Engl J Med. (2018) 379:341-51. doi: 10.1056/NEJMoa1805131

3. Cemiplimab Approved for Treatment of CSCC (2018). Cancer Discov. 8:OF2. doi: 10.1158/2159-8290.CD-NB2018-140

4. Cogdill AP, Andrews MC, Wargo JA. Hallmarks of response to immune checkpoint blockade. Br J Cancer. (2017) 117:1-7. doi: 10.1038/bjc.2017.136

5. MacGregor HL, Ohashi PS. Molecular pathways: evaluating the potential for B7-H4 as an immunoregulatory target. Clin Cancer Res. (2017) 23:2934-41. doi: 10.1158/1078-0432.CCR-15-2440

6. Yun S, Vincelette ND, Green MR, Wahner Hendrickson AE, Abraham I. Targeting immune checkpoints in unresectable metastatic cutaneous melanoma: a systematic review and meta-analysis of anti-CTLA-4 and antiPD-1 agents trials. Cancer Med. (2016) 5:1481-91. doi: 10.1002/cam4.732

7. Lu J, Lee-Gabel L, Nadeau MC, Ferencz TM, Soefje SA. Clinical evaluation of compounds targeting PD-1/PD-L1 pathway for cancer immunotherapy. $J$ Oncol Pharm Pract. (2015) 21:451-67. doi: 10.1177/1078155214538087

8. Sharma P, Hu-Lieskovan S, Wargo JA, Ribas A. Primary, adaptive, and acquired resistance to cancer immunotherapy. Cell. (2017) 168:707-23. doi: 10.1016/j.cell.2017.01.017

9. Zaretsky JM, Garcia-Diaz A, Shin DS, Escuin-Ordinas H, Hugo W, Hu-Lieskovan S, et al. Mutations associated with acquired resistance to PD-1 blockade in melanoma. $N$ Engl J Med. (2016) 375:819-29. doi: 10.1056/NEJMoa1604958

10. Luke JJ, Flaherty KT, Ribas A, Long GV. Targeted agents and immunotherapies: optimizing outcomes in melanoma. Nat Rev Clin Oncol. (2017) 14:463-82. doi: 10.1038/nrclinonc.2017.43

11. Baumeister SH, Freeman GJ, Dranoff G, Sharpe AH. Coinhibitory pathways in immunotherapy for cancer. Annu Rev Immunol. (2016) 34:539-73. doi: 10.1146/annurev-immunol-032414-112049

12. Fukumura D, Kloepper J, Amoozgar Z, Duda DG, Jain RK. Enhancing cancer immunotherapy using antiangiogenics: opportunities and challenges. Nat Rev Clin Oncol. (2018) 15:325-40. doi: 10.1038/nrclinonc.2018.29

13. Mahoney KM, Rennert PD, Freeman GJ. Combination cancer immunotherapy and new immunomodulatory targets. Nat Rev Drug Discov. (2015) 14:561-84. doi: 10.1038/nrd4591

14. Melero I, Berman DM, Aznar MA, Korman AJ, Perez Gracia JL, Haanen J. Evolving synergistic combinations of targeted immunotherapies to combat cancer. Nat Rev Cancer. (2015) 15:457-72. doi: 10.1038/nrc3973

15. Smyth MJ, Ngiow SF, Ribas A, Teng MW. Combination cancer immunotherapies tailored to the tumour microenvironment. Nat Rev Clin Oncol. (2016) 13:143-58. doi: 10.1038/nrclinonc.2015.209

16. Morrissey KM, Yuraszeck TM, Li CC, Zhang Y, Kasichayanula S. Immunotherapy and novel combinations in oncology: current landscape, challenges, and opportunities. Clin Transl Sci. (2016) 9:89-104. doi: $10.1111 /$ cts.12391

17. Bates SE. Refining immunotherapy approvals. Clin Cancer Res. (2017) 23:4948-9. doi: 10.1158/1078-0432.CCR-17-2025

18. Lhuillier C, Vanpouille-Box C, Galluzzi L, Formenti SC, Demaria S. Emerging biomarkers for the combination of radiotherapy and immune checkpoint blockers. Semin Cancer Biol. (2018) 52(Pt. 2):125-34. doi: 10.1016/j.semcancer.2017.12.007

19. Lesterhuis WJ, Bosco A, Millward MJ, Small M, Nowak AK, Lake RA. Dynamic versus static biomarkers in cancer immune checkpoint blockade: unravelling complexity. Nat Rev Drug Discov. (2017) 16:264-72. doi: $10.1038 / \mathrm{nrd} .2016 .233$

\section{ACKNOWLEDGMENTS}

I would like to acknowledge Maria Heise for excellent secretarial help and Michael Friedrich for preparing the figure.

20. Pulluri B, Kumar A, Shaheen M, Jeter J, Sundararajan S. Tumor microenvironment changes leading to resistance of immune checkpoint inhibitors in metastatic melanoma and strategies to overcome resistance. Pharmacol Res. (2017) 123:95-102. doi: 10.1016/j.phrs.2017.07.006

21. Melero I, Grimaldi AM, Perez-Gracia JL, Ascierto PA. Clinical development of immunostimulatory monoclonal antibodies and opportunities for combination. Clin Cancer Res. (2013) 19:997-1008. doi: 10.1158/1078-0432.CCR-12-2214

22. Dempke WCM, Fenchel K, Uciechowski P, Dale SP. Second- and thirdgeneration drugs for immuno-oncology treatment-The more the better? Eur J Cancer. (2017) 74:55-72. doi: 10.1016/j.ejca.2017.01.001

23. Wolchok JD, Kluger H, Callahan MK, Postow MA, Rizvi NA, Lesokhin AM, et al. Nivolumab plus ipilimumab in advanced melanoma. $N$ Engl J Med. (2013) 369:122-33. doi: 10.1056/NEJMoa1302369

24. Postow MA, Chesney J, Pavlick AC, Robert C, Grossmann K, McDermott D, et al. Nivolumab and ipilimumab versus ipilimumab in untreated melanoma. N Engl J Med. (2015) 372:2006-17. doi: 10.1056/NEJMoa1414428

25. Xu J, Zhang Q, Tian K, Wang H, Yin H, Zheng J. Current status and future prospects of the strategy of combining CART with PD1 blockade for antitumor therapy (Review). Mol Med Rep. (2018) 17:2083-8. doi: $10.3892 / \mathrm{mmr} .2017 .8129$

26. Wang $Y$, Zhang L, Xu Z, Miao L, Huang L. mRNA vaccine with antigen-specific checkpoint blockade induces an enhanced immune response against established melanoma. Mol Ther. (2018) 26:420-34. doi: 10.1016/j.ymthe.2017.11.009

27. Foley KC, Nishimura MI, Moore TV. Combination immunotherapies implementing adoptive T-cell transfer for advanced-stage melanoma. Melanoma Res. (2018) 28:171-84. doi: 10.1097/CMR.0000000000000436

28. Duperret EK, Wise MC, Trautz A, Villarreal DO, Ferraro B, Walters J, et al. Synergy of immune checkpoint blockade with a novel synthetic consensus DNA vaccine targeting TERT. Mol Ther. (2018) 26:435-45. doi: 10.1016/j.ymthe.2017.11.010

29. Ferris RL, Lenz HJ, Trotta AM, Garcia-Foncillas J, Schulten J, Audhuy F, et al. Rationale for combination of therapeutic antibodies targeting tumor cells and immune checkpoint receptors: harnessing innate and adaptive immunity through IgG1 isotype immune effector stimulation. Cancer Treat Rev. (2018) 63:48-60. doi: 10.1016/j.ctrv.2017.11.008

30. Chow LQM, Morishima C, Eaton KD, Baik CS, Goulart BH, Anderson LN, et al. Phase Ib trial of the toll-like receptor 8 agonist, motolimod (VTX2337), combined with cetuximab in patients with recurrent or metastatic SCCHN. Clin Cancer Res. (2017) 23:2442-50. doi: 10.1158/1078-0432.CCR16-1934

31. Lo Nigro C, Ricci V, Vivenza D, Monteverde M, Strola G, Lucio F, et al. Evaluation of antibody-dependent cell-mediated cytotoxicity activity and cetuximab response in KRAS wild-type metastatic colorectal cancer patients. World J Gastrointest Oncol. (2016) 8:222-30. doi: 10.4251/wjgo.v8.i2.222

32. Trotta AM, Ottaiano A, Romano C, Nasti G, Nappi A, De Divitiis $\mathrm{C}$, et al. Prospective evaluation of cetuximab-mediated antibodydependent cell cytotoxicity in metastatic colorectal cancer patients predicts treatment efficacy. Cancer Immunol Res. (2016) 4:366-74. doi: 10.1158/2326-6066.CIR-15-0184

33. Pahl JH, Ruslan SE, Buddingh EP, Santos SJ, Szuhai K, Serra M, et al. Anti-EGFR antibody cetuximab enhances the cytolytic activity of natural killer cells toward osteosarcoma. Clin Cancer Res. (2012) 18:432-41. doi: 10.1158/1078-0432.CCR-11-2277

34. McLaughlin P, Grillo-Lopez AJ, Link BK, Levy R, Czuczman MS, Williams ME, et al. Rituximab chimeric anti-CD20 monoclonal antibody therapy for relapsed indolent lymphoma: half of patients respond to a four-dose treatment program. J Clin Oncol. (1998) 16:2825-33. doi: 10.1200/JCO.1998.16.8.2825 
35. Wang L, Wei Y, Fang W, Lu C, Chen J, Cui G, et al. Cetuximab enhanced the cytotoxic activity of immune cells during treatment of colorectal cancer. Cell Physiol Biochem. (2017) 44:1038-50. doi: 10.1159/0004 85404

36. Formenti SC, Demaria S. Systemic effects of local radiotherapy. Lancet Oncol. (2009) 10:718-26. doi: 10.1016/S1470-2045(09)70082-8

37. Huguenin PU, Kieser S, Glanzmann C, Capaul R, Lutolf UM. Radiotherapy for metastatic carcinomas of the kidney or melanomas: an analysis using palliative end points. Int J Radiat Oncol Biol Phys. (1998) 41:401-5. doi: 10.1016/S0360-3016(98)00021-2

38. Khalil DN, Smith EL, Brentjens RJ, Wolchok JD. The future of cancer treatment: immunomodulation, CARs and combination immunotherapy. Nat Rev Clin Oncol. (2016) 13:273-90. doi: 10.1038/nrclinonc.2016.25

39. Marshall HT, Djamgoz MBA. Immuno-oncology: emerging targets and combination therapies. Front Oncol. (2018) 8:315. doi: 10.3389/fonc.2018.00315

40. Wargo JA, Reuben A, Cooper ZA, Oh KS, Sullivan RJ. Immune effects of chemotherapy, radiation, and targeted therapy and opportunities for combination with immunotherapy. Semin Oncol. (2015) 42:601-16. doi: 10.1053/j.seminoncol.2015.05.007

41. Deng L, Liang H, Xu M, Yang X, Burnette B, Arina A, et al. STING-dependent cytosolic dna sensing promotes radiation-induced type i interferondependent antitumor immunity in immunogenic tumors. Immunity. (2014) 41:843-52. doi: 10.1016/j.immuni.2014.10.019

42. Lugade AA, Sorensen EW, Gerber SA, Moran JP, Frelinger JG, Lord EM. Radiation-induced IFN-gamma production within the tumor microenvironment influences antitumor immunity. J Immunol. (2008) 180:3132-9. doi: 10.4049/jimmunol.180.5.3132

43. Fuertes MB, Kacha AK, Kline J, Woo SR, Kranz DM, Murphy KM, et al. Host type I IFN signals are required for antitumor CD8+ T cell responses through CD8\{alpha\}+ dendritic cells. J Exp Med. (2011) 208:2005-16. doi: 10.1084/jem.20101159

44. Santin AD, Hermonat PL, Hiserodt JC, Chiriva-Internati M, Woodliff J, Theus JW, et al. Effects of irradiation on the expression of major histocompatibility complex class I antigen and adhesion costimulation molecules ICAM-1 in human cervical cancer. Int J Radiat Oncol Biol Phys. (1997) 39:737-42. doi: 10.1016/S0360-3016(97)00372-6

45. Santin AD, Rose GS, Hiserodt JC, Fruehauf J, Eck LM, Garcia RI, et al. Effects of cytokines combined with high-dose gamma irradiation on the expression of major histocompatibility complex molecules and intercellular adhesion molecule-1 in human ovarian cancers. Int J Cancer. (1996) 65:688-94. doi: 10.1002/(SICI)1097-0215(19960301)65:5\&lt;688::AIDIJC21\&gt;3.0.CO;2-2

46. Chakraborty M, Abrams SI, Camphausen K, Liu K, Scott T, Coleman CN, et al. Irradiation of tumor cells up-regulates Fas and enhances CTL lytic activity and CTL adoptive immunotherapy. J Immunol. (2003) 170:6338-47. doi: 10.4049/jimmunol.170.12.6338

47. Saito H, Tsujitani S, Oka S, Kondo A, Ikeguchi M, Maeta M, et al. An elevated serum level of transforming growth factor-beta 1 (TGF-beta 1) significantly correlated with lymph node metastasis and poor prognosis in patients with gastric carcinoma. Anticancer Res. (2000) 20:4489-93.

48. Filatenkov A, Baker J, Mueller AM, Kenkel J, Ahn GO, Dutt S, et al. Ablative tumor radiation can change the tumor immune cell microenvironment to induce durable complete remissions. Clin Cancer Res. (2015) 21:3727-39. doi: 10.1158/1078-0432.CCR-14-2824

49. Sceneay J, Chow MT, Chen A, Halse HM, Wong CS, Andrews DM, et al. Primary tumor hypoxia recruits CD11b+/Ly6Cmed/Ly6G+ immune suppressor cells and compromises NK cell cytotoxicity in the premetastatic niche. Cancer Res. (2012) 72:3906-11. doi: 10.1158/0008-5472.CAN-11-3873

50. Doedens AL, Stockmann C, Rubinstein MP, Liao D, Zhang N, DeNardo DG, et al. Macrophage expression of hypoxia-inducible factor-1 alpha suppresses T-cell function and promotes tumor progression. Cancer Res. (2010) 70:7465-75. doi: 10.1158/0008-5472.CAN-10-1439

51. Deng L, Liang H, Burnette B, Weicheslbaum RR, Fu YX. Radiation and antiPD-L1 antibody combinatorial therapy induces T cell-mediated depletion of myeloid-derived suppressor cells and tumor regression. Oncoimmunology. (2014) 3:e28499. doi: 10.4161/onci.28499
52. Vanpouille-Box C, Formenti SC, Demaria S. Toward precision radiotherapy for use with immune checkpoint blockers. Clin Cancer Res. (2018) 24:259-65. doi: 10.1158/1078-0432.CCR-16-0037

53. Rudqvist NP, Pilones KA, Lhuillier C, Wennerberg E, Sidhom JW, Emerson RO, et al. Radiotherapy and CTLA- 4 blockade shape the TCR repertoire of tumor-infiltrating T cells. Cancer Immunol Res. (2018) 6:139-50. doi: 10.1158/2326-6066.CIR-17-0134

54. Formenti SC, Lee P, Adams S, Goldberg JD, Li X, Xie MW, et al. Focal irradiation and systemic TGFbeta blockade in metastatic breast cancer. Clin Cancer Res. (2018) 24:2493-504. doi: 10.1158/1078-0432.CCR-17-3322

55. Vanpouille-Box C, Alard A, Aryankalayil MJ, Sarfraz Y, Diamond JM, Schneider RJ, et al. DNA exonuclease Trexl regulates radiotherapyinduced tumour immunogenicity. Nat Commun. (2017) 8:15618. doi: $10.1038 /$ ncomms15618

56. Golden EB, Demaria S, Schiff PB, Chachoua A, Formenti SC. An abscopal response to radiation and ipilimumab in a patient with metastatic non-small cell lung cancer. Cancer Immunol Res. (2013) 1:365-72. doi: 10.1158/2326-6066.CIR-13-0115

57. Kang J, Demaria S, Formenti S. Current clinical trials testing the combination of immunotherapy with radiotherapy. J Immunother Cancer. (2016) 4:51. doi: 10.1186/s40425-016-0156-7

58. Wennerberg E, Vanpouille-Box C, Bornstein S, Yamazaki T, Demaria S, Galluzzi L. Immune recognition of irradiated cancer cells. Immunol Rev. (2017) 280:220-30. doi: 10.1111/imr.12568

59. Antonia SJ, Villegas A, Daniel D, Vicente D, Murakami S, Hui R, et al. Durvalumab after chemoradiotherapy in stage III non-small-cell lung cancer. N Engl J Med. (2017) 377:1919-29. doi: 10.1056/NEJMoa1709937

60. Vanpouille-Box C, Pilones KA, Wennerberg E, Formenti SC, Demaria S. In situ vaccination by radiotherapy to improve responses to anti-CTLA-4 treatment. Vaccine. (2015) 33:7415-22. doi: 10.1016/j.vaccine.2015.05.105

61. Morris ZS, Guy EI, Francis DM, Gressett MM, Werner LR, Carmichael $\mathrm{LL}$, et al. In situ tumor vaccination by combining local radiation and tumor-specific antibody or immunocytokine treatments. Cancer Res. (2016) 76:3929-41. doi: 10.1158/0008-5472.CAN-15-2644

62. Bracci L, Schiavoni G, Sistigu A, Belardelli F. Immune-based mechanisms of cytotoxic chemotherapy: implications for the design of novel and rationalebased combined treatments against cancer. Cell Death Differ. (2014) 21:1525. doi: $10.1038 / \mathrm{cdd} .2013 .67$

63. Iida Y, Harashima N, Motoshima T, Komohara Y, Eto M, Harada M. Contrasting effects of cyclophosphamide on anti-CTL-associated protein 4 blockade therapy in two mouse tumor models. Cancer Sci. (2017) 108:197484. doi: $10.1111 /$ cas.13337

64. Reck M, Bondarenko I, Luft A, Serwatowski P, Barlesi F, Chacko R, et al. Ipilimumab in combination with paclitaxel and carboplatin as firstline therapy in extensive-disease-small-cell lung cancer: results from a randomized, double-blind, multicenter phase 2 trial. Ann Oncol. (2013) 24:75-83. doi: 10.1093/annonc/mds213

65. Xu X, Huang Z, Zheng L, Fan Y. The efficacy and safety of anti-PD-1/PDL1 antibodies combined with chemotherapy or CTLA4 antibody as a firstline treatment for advanced lung cancer. Int J Cancer. (2018) 142:2344-54. doi: 10.1002/ijc.31252

66. Gandhi L, Rodriguez-Abreu D, Gadgeel S, Esteban E, Felip E, De Angelis F, et al. Pembrolizumab plus chemotherapy in metastatic non-small-cell lung cancer. N Engl J Med. (2018) 378:2078-2092. doi: 10.1056/NEJMoa1801005

67. Seliger B, Massa C, Rini B, Ko J, Finke J. Antitumour and immune-adjuvant activities of protein-tyrosine kinase inhibitors. Trends Mol Med. (2010) 16:184-92. doi: 10.1016/j.molmed.2010.02.001

68. Missiaen R, Mazzone M, Bergers G. The reciprocal function and regulation of tumor vessels and immune cells offers new therapeutic opportunities in cancer. Semin Cancer Biol. (2018) 52(Pt. 2):107-16. doi: 10.1016/j.semcancer.2018.06.002

69. Hato T, Zhu AX, Duda DG. Rationally combining anti-VEGF therapy with checkpoint inhibitors in hepatocellular carcinoma. Immunotherapy. (2016) 8:299-313. doi: 10.2217/imt.15.126

70. Jain RK. Antiangiogenesis strategies revisited: from starving tumors to alleviating hypoxia. Cancer Cell. (2014) 26:605-22. doi: 10.1016/j.ccell.2014.10.006 
71. Heist RS, Duda DG, Sahani DV, Ancukiewicz M, Fidias P, Sequist LV, et al. Improved tumor vascularization after anti-VEGF therapy with carboplatin and nab-paclitaxel associates with survival in lung cancer. Proc Natl Acad Sci USA. (2015) 112:1547-52. doi: 10.1073/pnas.1424024112

72. Chauhan VP, Martin JD, Liu H, Lacorre DA, Jain SR, Kozin SV et al. Angiotensin inhibition enhances drug delivery and potentiates chemotherapy by decompressing tumour blood vessels. Nat Commun. (2013) 4:2516. doi: $10.1038 /$ ncomms3516

73. Shrimali RK, Yu Z, Theoret MR, Chinnasamy D, Restifo NP, Rosenberg SA. Antiangiogenic agents can increase lymphocyte infiltration into tumor and enhance the effectiveness of adoptive immunotherapy of cancer. Cancer Res. (2010) 70:6171-80. doi: 10.1158/0008-5472.CAN-10-0153

74. Pircher A, Wolf D, Heidenreich A, Hilbe W, Pichler R, Heidegger I. Synergies of targeting tumor angiogenesis and immune checkpoints in non-small cell lung cancer and renal cell cancer: from basic concepts to clinical reality. Int $J$ Mol Sci. (2017) 18:2291. doi: 10.3390/ijms18112291

75. Kuusk T, Albiges L, Escudier B, Grivas N, Haanen J, Powles T et al. Antiangiogenic therapy combined with immune checkpoint blockade in renal cancer. Angiogenesis. (2017) 20:205-15. doi: 10.1007/s10456-017-9550-0

76. Ribas A, Hodi FS, Callahan M, Konto C, Wolchok J. Hepatotoxicity with combination of vemurafenib and ipilimumab. N Engl J Med. (2013) 368:1365-6. doi: 10.1056/NEJMc1302338

77. Hu-Lieskovan S, Robert L, Homet Moreno B, Ribas A. Combining targeted therapy with immunotherapy in BRAF-mutant melanoma: promise and challenges. J Clin Oncol. (2014) 32:2248-54. doi: 10.1200/JCO.2013. 52.1377

78. Hughes PE, Caenepeel S, Wu LC. Targeted therapy and checkpoint immunotherapy combinations for the treatment of cancer. Trends Immunol. (2016) 37:462-76. doi: 10.1016/j.it.2016.04.010

79. De Henau O, Rausch M, Winkler D, Campesato LF, Liu C, Cymerman $\mathrm{DH}$ et al. Overcoming resistance to checkpoint blockade therapy by targeting PI3Kgamma in myeloid cells. Nature. (2016) 539:443-7. doi: 10.1038/nature20554

80. Neubert NJ, Schmittnaegel M, Bordry N, Nassiri S, Wald N, Martignier C, et al. T cell-induced CSF1 promotes melanoma resistance to PD1 blockade. Sci Transl Med. (2018) 10:eaan3311. doi: 10.1126/scitranslmed.aan3311

81. Goel S, DeCristo MJ, Watt AC, BrinJones H, Sceneay J, Li BB, et al. CDK4/6 inhibition triggers anti-tumour immunity. Nature. (2017) 548:4715. doi: 10.1038/nature23465

82. Patnaik A, Rosen LS, Tolaney SM, Tolcher AW, Goldman JW, Gandhi L et al. Efficacy and safety of abemaciclib, an inhibitor of CDK4 and CDK6, for patients with breast cancer, non-small cell lung cancer, and other solid tumors. Cancer Discov. (2016) 6:740-53. doi: 10.1158/2159-8290.CD-16-0095

83. Schaer DA, Beckmann RP, Dempsey JA, Huber L, Forest A, Amaladas N, et al. The CDK4/6 inhibitor abemaciclib induces a t cell inflamed tumor microenvironment and enhances the efficacy of PD-L1 checkpoint blockade. Cell Rep. (2018) 22:2978-94. doi: 10.1016/j.celrep.2018.02.053

84. Stone ML, Chiappinelli KB, Li H, Murphy LM, Travers ME, Topper MJ, et al. Epigenetic therapy activates type I interferon signaling in murine ovarian cancer to reduce immunosuppression and tumor burden. Proc Natl Acad Sci USA. (2017) 114:E10981-90. doi: 10.1073/pnas.1712514114

85. Zahnow CA, Topper M, Stone M, Murray-Stewart T, Li H, Baylin SB, et al. Inhibitors of DNA methylation, histone deacetylation, and histone demethylation: a perfect combination for cancer therapy. Adv Cancer Res. (2016) 130:55-111. doi: 10.1016/bs.acr.2016.01.007

86. Orskov AD, Treppendahl MB, Skovbo A, Holm MS, Friis LS, Hokland M, et al. Hypomethylation and up-regulation of PD-1 in T cells by azacytidine in MDS/AML patients: a rationale for combined targeting of PD-1 and DNA methylation. Oncotarget. (2015) 6:9612-26. doi: 10.18632/oncotarget.3324

87. Raulet DH, Guerra N. Oncogenic stress sensed by the immune system: role of natural killer cell receptors. Nat Rev Immunol. (2009) 9:568-80. doi: $10.1038 /$ nri2604

88. Farag SS, Caligiuri MA. Immunologic approaches to acute leukemia in the elderly. Semin Hematol. (2006) 43:118-25. doi: 10.1053/j.seminhematol.2006.01.006
89. Farag SS, Fehniger TA, Ruggeri L, Velardi A, Caligiuri MA. Natural killer cell receptors: new biology and insights into the graft-versus-leukemia effect. Blood. (2002) 100:1935-47. doi: 10.1182/blood-2002-02-0350

90. Cooper MA, Fehniger TA, Caligiuri MA. The biology of human natural killer-cell subsets. Trends Immunol. (2001) 22:633-40. doi: 10.1016/S1471-4906(01)02060-9

91. He Y, Liu S, Mattei J, Bunn PA Jr, Zhou C, Chan D. The combination of antiKIR monoclonal antibodies with anti-PD-1/PD-L1 monoclonal antibodies could be a critical breakthrough in overcoming tumor immune escape in NSCLC. Drug Des Devel Ther. (2018) 12:981-6. doi: 10.2147/DDDT.S163304

92. Wang S, Campos J, Gallotta M, Gong M, Crain C, Naik E, et al. Intratumoral injection of a CpG oligonucleotide reverts resistance to PD-1 blockade by expanding multifunctional CD8+ T cells. Proc Natl Acad Sci USA. (2016) 113:E7240-9. doi: 10.1073/pnas.1608555113

93. Hemmi H, Kaisho T, Takeuchi O, Sato S, Sanjo H, Hoshino K, et al. Small anti-viral compounds activate immune cells via the TLR7 MyD88-dependent signaling pathway. Nat Immunol. (2002) 3:196-200. doi: 10.1038/ni758

94. van Duin D, Medzhitov R, Shaw AC. Triggering TLR signaling in vaccination. Trends Immunol. (2006) 27:49-55. doi: 10.1016/j.it.2005.11.005

95. Lu H, Dietsch GN, Matthews MA, Yang Y, Ghanekar S, Inokuma $\mathrm{M}$, et al. VTX-2337 is a novel TLR8 agonist that activates NK cells and augments ADCC. Clin Cancer Res. (2012) 18:499-509. doi: 10.1158/1078-0432.CCR-11-1625

96. Prins RM, Craft N, Bruhn KW, Khan-Farooqi H, Koya RC, Stripecke $\mathrm{R}$, et al. The TLR-7 agonist, imiquimod, enhances dendritic cell survival and promotes tumor antigen-specific $\mathrm{T}$ cell priming: relation to central nervous system antitumor immunity. J Immunol. (2006) 176:157-64. doi: 10.4049/jimmunol.176.1.157

97. Whitmore MM, DeVeer MJ, Edling A, Oates RK, Simons B, Lindner D, et al. Synergistic activation of innate immunity by double-stranded RNA and CpG DNA promotes enhanced antitumor activity. Cancer Res. (2004) 64:5850-60. doi: 10.1158/0008-5472.CAN-04-0063

98. Sato-Kaneko F, Yao S, Ahmadi A, Zhang SS, Hosoya T, Kaneda MM, et al. Combination immunotherapy with TLR agonists and checkpoint inhibitors suppresses head and neck cancer. JCI Insight. (2017) 2:e93397. doi: 10.1172/jci.insight.93397

99. Bhome R, Bullock MD, Al Saihati HA, Goh RW, Primrose JN, Sayan AE, et al. A top-down view of the tumor microenvironment: structure, cells and signaling. Front Cell Dev Biol. (2015) 3:33. doi: 10.3389/fcell.2015.00033

100. Kalluri R. The biology and function of fibroblasts in cancer. Nat Rev Cancer. (2016) 16:582-98. doi: 10.1038/nrc.2016.73

101. Sangaletti S, Chiodoni C, Tripodo C, Colombo MP. The good and bad of targeting cancer-associated extracellular matrix. Curr Opin Pharmacol. (2017) 35:75-82. doi: 10.1016/j.coph.2017.06.003

102. Owyong M, Efe G, Owyong M, Abbasi AJ, Sitarama V, Plaks V. Overcoming barriers of age to enhance efficacy of cancer immunotherapy: the clout of the extracellular matrix. Front Cell Dev Biol. (2018) 6:19. doi: $10.3389 /$ fcell.2018.00019

103. Li M, Xing S, Zhang H, Shang S, Li X, Ren B et al. A matrix metalloproteinase inhibitor enhances anti-cytotoxic $\mathrm{T}$ lymphocyte antigen-4 antibody immunotherapy in breast cancer by reprogramming the tumor microenvironment. Oncol Rep. (2016) 35:1329-39. doi: 10.3892/or.2016.4547

104. Ohshio Y, Teramoto K, Hanaoka J, Tezuka N, Itoh Y, Asai T, et al. Cancer-associated fibroblast-targeted strategy enhances antitumor immune responses in dendritic cell-based vaccine. Cancer Sci. (2015) 106:134-42. doi: $10.1111 /$ cas. 12584

105. Dannenberg AJ, Subbaramaiah K. Targeting cyclooxygenase- 2 in human neoplasia: rationale and promise. Cancer Cell. (2003) 4:431-6. doi: 10.1016/S1535-6108(03)00310-6

106. Wang D, Dubois RN. Eicosanoids and cancer. Nat Rev Cancer. (2010) 10:181-93. doi: 10.1038/nrc2809

107. Zelenay S, van der Veen AG, Bottcher JP, Snelgrove KJ, Rogers N, Acton SE, et al. Cyclooxygenase-Dependent Tumor Growth through Evasion of Immunity. Cell. (2015) 162:1257-70. doi: 10.1016/j.cell.2015.08.015

108. Markosyan N, Chen EP, Smyth EM. Targeting COX-2 abrogates mammary tumorigenesis: breaking cancer-associated suppression 
of immunosurveillance. Oncoimmunology. (2014) 3:e29287. doi: 10.4161/onci.29287

109. Marleau AM, Chen CS, Joyce JA, Tullis RH. Exosome removal as a therapeutic adjuvant in cancer. J Transl Med. (2012) 10:134. doi: 10.1186/1479-5876-10-134

110. Wolfers J, Lozier A, Raposo G, Regnault A, Thery C, Masurier C, et al. Tumor-derived exosomes are a source of shared tumor rejection antigens for CTL cross-priming. Nat Med. (2001) 7:297-303. doi: 10.1038/85438

111. Li Q, Huang Q, Huyan T, Wang Y, Huang Q, Shi J. Bifacial effects of engineering tumour cell-derived exosomes on human natural killer cells. Exp Cell Res. (2018) 363:141-50. doi: 10.1016/j.yexcr.2017.12.005

112. Nakamura K, Sawada K, Kinose Y, Yoshimura A, Toda A, Nakatsuka E, et al. Exosomes promote ovarian cancer cell invasion through transfer of CD44 to peritoneal mesothelial cells. Mol Cancer Res. (2017) 15:78-92. doi: 10.1158/1541-7786.MCR-16-0191

113. Zheng H, Liu X, Zhang J, Rice SJ, Wagman M, Kong Y, et al. Expression of PD-1 on CD4+ T cells in peripheral blood associates with poor clinical outcome in non-small cell lung cancer. Oncotarget. (2016) 7:56233-40. doi: 10.18632/oncotarget.9316

114. Tanizaki J, Haratani K, Hayashi H, Chiba Y, Nakamura Y, Yonesaka K, et al. Peripheral blood biomarkers associated with clinical outcome in non-small cell lung cancer patients treated with nivolumab. J Thorac Oncol. (2018) 13:97-105. doi: 10.1016/j.jtho.2017.10.030

115. Choueiri TK, Fishman MN, Escudier B, McDermott DF, Drake $\mathrm{CG}$, Kluger $\mathrm{H}$, et al. Immunomodulatory activity of nivolumab in metastatic renal cell carcinoma. Clin Cancer Res. (2016) 22:5461-71. doi: 10.1158/1078-0432.CCR-15-2839

116. Jacquelot N, Roberti MP, Enot DP, Rusakiewicz S, Ternes N, Jegou $\mathrm{S}$, et al. Predictors of responses to immune checkpoint blockade in advanced melanoma. Nat Commun. (2017) 8:592. doi: 10.1038/s41467-01700608-2

117. Martens A, Wistuba-Hamprecht K, Geukes Foppen M, Yuan J, Postow MA, Wong $\mathrm{P}$, et al. Baseline peripheral blood biomarkers associated with clinical outcome of advanced melanoma patients treated with ipilimumab. Clin Cancer Res. (2016) 22:2908-18. doi: 10.1158/1078-0432.CCR-15-2412

118. Ji RR, Chasalow SD, Wang L, Hamid O, Schmidt H, Cogswell J, et al. An immune-active tumor microenvironment favors clinical response to ipilimumab. Cancer Immunol Immunother. (2012) 61:1019-31. doi: 10.1007/s00262-011-1172-6

119. Madonna G, Ballesteros-Merino C, Feng Z, Bifulco C, Capone M, Giannarelli $\mathrm{D}$, et al. PD-L1 expression with immune-infiltrate evaluation and outcome prediction in melanoma patients treated with ipilimumab. Oncoimmunology. (2018) 7:e1405206. doi: 10.1080/2162402X.2017.1405206

120. Page DB, Yuan J, Redmond D, Wen YH, Durack JC, Emerson R, et al. Deep sequencing of T-cell receptor DNA as a biomarker of clonally expanded TILs in breast cancer after immunotherapy. Cancer Immunol Res. (2016) 4:835-44. doi: 10.1158/2326-6066.CIR-16-0013

121. Siemers NO, Holloway JL, Chang H, Chasalow SD, Ross-MacDonald $\mathrm{PB}$, Voliva CF, et al. Genome-wide association analysis identifies genetic correlates of immune infiltrates in solid tumors. PLoS ONE. (2017) 12:e179726. doi: 10.1371/journal.pone.0179726

122. Krieg C, Nowicka M, Guglietta S, Schindler S, Hartmann FJ, Weber LM, et al. High-dimensional single-cell analysis predicts response to anti-PD-1 immunotherapy. Nat Med. (2018) 24:144-53. doi: 10.1038/ nm.4466

Conflict of Interest Statement: The author declares that the research was conducted in the absence of any commercial or financial relationships that could be construed as a potential conflict of interest.

Copyright (c) 2019 Seliger. This is an open-access article distributed under the terms of the Creative Commons Attribution License (CC BY). The use, distribution or reproduction in other forums is permitted, provided the original author $(s)$ and the copyright owner(s) are credited and that the original publication in this journal is cited, in accordance with accepted academic practice. No use, distribution or reproduction is permitted which does not comply with these terms. 